\title{
HeartMate 3: Bridging from clinical trial experience to real-world use
}

\author{
Daniel J. Goldstein, MD
}

\footnotetext{
From the Department of Cardiovascular and Thoracic Surgery, Montefiore Medical Center, Albert Einstein College of Medicine, Bronx, NY.

Disclosures: Author has served as National Principal Investigator for the MOMENTUM 3 clinical trial and received travel expense reimbursement for attendance at principal investigator meetings.

Received for publication March 2, 2018; accepted for publication March 7, 2018; available ahead of print April 3 , 2018.

Address for reprints: Daniel J. Goldstein, MD, Department of Cardiovascular and Thoracic Surgery, Montefiore Medical Center, Albert Einstein College of Medicine, 3400 Bainbridge Ave, MAP 5, Bronx, NY 10467 (E-mail: dgoldste@montefiore.org).

J Thorac Cardiovasc Surg 2018;156:660-1

$0022-5223 / \$ 36.00$

Copyright (c) 2018 by The American Association for Thoracic Surgery

https://doi.org/10.1016/j.jtcvs.2018.03.028
}

Experience is the name everyone gives to their mistakes.

$$
\begin{gathered}
\text {-Oscar Wilde } \\
\text { Lady Windermere's Fan }
\end{gathered}
$$

In the article in this issue of the Journal from the Hannover Medical School, an institution with a long history of leadership in the field of mechanical circulatory support, Hanke and colleagues ${ }^{1}$ describe their center's experience with 27 patients undergoing HeartMate 3 (St Jude Medical Inc, St Paul, Minn) support, most of whom $(n=19)$ had the devices implanted after completion of the CE Mark trial. This cohort thus represents the largest reported real-world experience with the HeartMate 3 device.

When comparing this real-world cohort with that of the original CE Mark trial, ${ }^{2}$ several consistencies are evident. Both were designed as all-comer studies. Both undertook the implant procedure through a conventional sternotomy under cardiopulmonary bypass support. In both, there was a marked predominance of men and Interagency Registry for Mechanically Assisted Circulatory Support profile 3, with similar baseline filling pressures and low incidences of previous sternotomy. Similar antithrombotic strategies were used in both trials, with early initiation of heparin, bridging to a vitamin $\mathrm{K}$ antagonist with a target international normalized ratio of 2 to 3 , and use of low-dose aspirin.

Despite these commonalities, a comparison of outcomes suggests an improvement with the transition from initial clinical trial experience-with its obligatory learning curve - to real-world use. Postoperative length of stay was reduced. At 1 year, the incidences of all bleeding events (30\% vs $44 \%$ ), gastrointestinal bleeding (3.7\% vs $12 \%)$, right-sided heart failure $(7.4 \%$ vs $10 \%)$, and stroke $(0 \%$ vs $18 \%$ ) all favored the real-world cohort. A rewarding absence of pump malfunctions, hemolysis, and pump

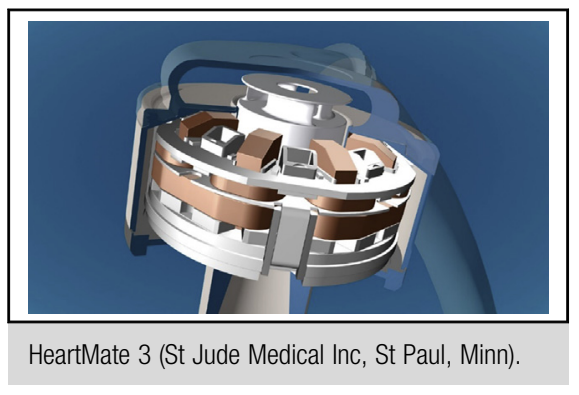

Central Message

It is imperative in the field of mechanical support to embrace new technologies and trials, to accept learning curves, and to continue to enhance techniques to optimize these lifesaving devices.

See Article page 662

thrombosis at 1 year was noted in both experiences. One-year survivals were $85.2 \%$ for the real-world cohort and $81 \%$ in the CE Mark experience.

Although the usual limitations associated with small cohorts, lack of randomization and limited follow up, are irrefutable, this early postapproval experience suggests that the learning curve inherent in new technologies is being overcome with the availability of the HeartMate 3 for commercial use in Europe and elsewhere. This observation should not come as a surprise, because comparable improvements have been well documented with other mechanical circulatory support technologies. Indeed, John and colleagues first described an increase in 1-year survival from $76 \%$ (trial) to $85 \%$ (posttrial) in HeartMate II bridge-totransplant recipients. Jorde and associates ${ }^{4}$ documented reduced incidence of bleeding and infectious complications as well as improved survival for HeartMate II destination therapy recipients after device approval. Data from a multicenter postmarket registry ${ }^{5}$ suggested improving outcomes for post-CE Mark trial HeartWare ventricular assist device recipients when compared with trial experience.

The field of mechanical support is unique in its inherent complexity of devices, associated adverse event profile, and severity of illness of the intended patient population. ${ }^{6}$ Moreover, successful outcomes can only be consistently achieved when a multidisciplinary team is reliably and longitudinally involved in the care of these frail patients. Although great strides have been made in raw survival and quality of life, the adverse event burden accompanying these technologies 
remains considerable. It is imperative that we embrace new technologies and trials, accept learning curves, and continue to enhance our surgical techniques and medical management to optimize the real-world application of these lifesaving and life-enhancing devices.

\section{References}

1. Hanke JS, Dogan G, Zoch A, Ricklefs M, Wert L, Feldmann C, et al. One-year outcomes with the HeartMate 3 left ventricular assist device. J Thorac Cardiovasc Surg. 2018;156:662-9.

2. Netuka I, Sood P, Pya Y, Zimpfer D, Krabatsch T, Garbade J, et al. Fully magnetically levitated left ventricular assist system for treating advanced heart failure: a multicenter study. J Am Coll Cardiol. 2015;66:2579-89.
3. John R, Kamdar F, Liao K, Colvin-Adams M, Boyle A, Joyce L. Improved surviva and decreasing incidence of adverse events with the HeartMate II left ventricular assist device as a bridge-to-transplant therapy. Ann Thorac Surg. 2008;86: 1227-34; discussion 1234-5.

4. Jorde UP, Kushwaha SS, Tatooles AJ, Naka Y, Bhat G, Long JW, et al; HeartMate II Clinical Investigators. Results of the destination therapy post-food and drug administration approval study with a continuous flow left ventricular assist device: a prospective study using the INTERMACS registry (interagency registry for mechanically assisted circulatory support). J Am Coll Cardiol. 2014;63:1751-7.

5. Strueber M, Larbalestier R, Jansz P, Zimpfer D, Fiane AE, Tsui S, et al. Results of the post-market registry to evaluate the HeartWare left ventricular assist system (ReVOLVE). J Heart Lung Transplant. 2014;33:486-91.

6. Acker MA, Pagani FD, Stough WG, Mann DL, Jessup M, Kormos R, et al. Statement regarding the pre and post market assessment of durable, implantable ventricular assist devices in the United States. J Heart Lung Transplant. 2012;31:1241-52. 